RESEARCH REPORT

\title{
LACK OF GENDER BIAS IN CITATION RATES OF PUBLICATIONS BY DENDROCHRONOLOGISTS: WHAT IS UNIQUE ABOUT THIS DISCIPLINE?
}

\author{
CAROLYN A. COPENHEAVER ${ }^{1 *}$, KYRILLE GOLDBECK ${ }^{2}$, and PAOLO CHERUBINI ${ }^{3}$ \\ ${ }^{1}$ Department of Forest Resources and Environmental Conservation, Virginia Tech, Blacksburg, VA 24061, USA \\ ${ }^{2}$ University Libraries, Virginia Tech, Blacksburg, VA 24061, USA \\ ${ }^{3}$ Swiss Federal Institute for Forestry, Snow, and Landscape Research (WSL), Züricherstrasse 111, CH-8903 Birmensdorf, \\ Switzerland
}

\begin{abstract}
Most academic disciplines have a gender bias that exists in the recognition of research publications: women's publications are cited at lower rates than men's publications. In this paper, we examined whether a similar gender bias existed for publications by dendrochronologists. Tree-ring research is a fairly small field where males outnumber females, and therefore the sample size was limited to 20 female dendrochronologists and 20 male dendrochronologists. It was determined that native language (English or non-native English speaker), current employment (government or academic), and gender of the first-author do not significantly influence a paper's probability of being cited. However, years since dissertation completion was a good predictor of a paper's citation rate. We suggest that the high productivity of female dendrochronologists and a pattern of co-authoring with male colleagues bring the work of females to the attention of their male colleagues and thus eliminate the gender bias in citation of women's work common to other disciplines.
\end{abstract}

Keywords: gender bias, citation, publishing, women in science.

\section{INTRODUCTION}

Women in academia and other research-related occupations face a higher number of obstacles toward achieving success than their male counterparts. These barriers have been documented in a wide variety of disciplines, but one barrier that has been gaining increasing interest involves whether women's scholarship receives equal recognition (as assessed by number of citations received) as men's scholarship (Stack 2002; Penas and Willett 2006). Regardless of the limits of bibliometric indicators (Cherubini 2008), recognition of an individual's work as represented by numbers of citations and impact factors are important in decisions for funding, promotion, and career advancement (Dries et al. 2008). Therefore, the question of whether

*Corresponding author: ccopenhe@vt.edu gender bias exists within a discipline becomes increasingly important. The cause of gender bias is complex and is generally a result of a combination of factors. Author seniority and name recognition are important factors that contribute significantly to increases in citation rates (Feramisco et al. 2009; Tol 2009). In many disciplines males outnumber females in the senior ranks of researchers; this coupled with name recognition can hinder the citation rates of women's scholarship. Additionally, men cite women's publications at a lower rate $(22 \%)$ than women cite women's publications (35\%) and given that male scholars dominate most academic disciplines, this results in lower citation rates for femaleauthored papers (McElhinny et al. 2003; Bredenkamp and Smith 2008). However, a lower citation rate does not mean that women produce poorer quality work. In the life sciences, males who consistently produced un-cited publications were 
able to maintain a successful career in the sciences, whereas women were required to produce high quality work in order to maintain their employment (Symonds et al. 2006).

Citations are commonly used as a metric to quantify professional recognition of scholarship. Although occasionally citations are used to discredit the original work, the majority of citations serve to fit the new piece of research into an existing infrastructure of scientific literature. Thus, for a researcher to publish data or findings that are never cited essentially isolates this individual and excludes them from participating as a functioning contributor to the research community. It is for this reason that gender bias in citation rates has been a documented, critical barrier to women's success in the social sciences, information sciences, life sciences, and the humanities (Davenport and Snyder 1995; McElhinny et al. 2003; Penas and Willett 2006; Symonds et al. 2006). Gender differences in citation rate appear to be discipline specific, so identifying whether a difference exists within a discipline is an important factor for making fair and equitable decisions regarding the evaluation and promotion of female and male researchers (Ward et al. 1992).

The objective of this study was to identify whether a gender bias in citation rate between male and female dendrochronologists exists. To further clarify the citation patterns in dendrochronology, we also examined the importance of the following factors: years since dissertation completion, native language (English or non-native English speaker), current employment (government or academic) and researcher productivity.

\section{APPROACH AND METHODS}

A relatively small population of researchers, whose work is often interdisciplinary, practices dendrochronology. The International Tree-Ring Data Bank (ITRDB) forum on the web has 664 subscribers of whom $70 \%$ are males and $30 \%$ are females. The International Tree-Ring Conference is hosted once every four years and is attended by dendrochronologists from a variety of disciplines including archaeology, biology, botany, ecophysiology, climatology, ecology, environmental science, forestry, geography, geology, hydrology, and related fields. The last conference was hosted in Beijing, China, and was attended by 317 researchers with $28 \%$ women and $72 \%$ men. The total number of dendrochronologists provided us with a manageable population to study, and a group that crossed several science-based disciplines.

Male dendrochronologists outnumber females, and therefore we used targeted sampling and let the number of female dendrochronologists determine our sample size. We used the Web of Science (copyright by the Institute for Scientific Information of Thomson Reuters) database to locate and identify 20 female scientists who had first-authored publications between the years 1990-2002 in the discipline of dendrochronology, by using the keywords "dendrochronology," "dendroclimatology," and "dendroecology." We searched for dendrochronologists within this time span because it provided female dendrochronologists who had been publishing in the discipline for at least seven years prior to 2009, thus increasing the likelihood of identifying women who had multiple publications. However, we included all first-authored publications from the entire career span from each dendrochronologist. As many researchers "straddled" more than one discipline, not all of their publications were directly related to dendrochronology. To address the breadth of their research areas, we only included researchers who employed dendrochronological methods in a majority of their published work. Additionally, as the length of time a researcher has been contributing publications is an important factor in citation rate (Tol 2009), we identified 20 male dendrochronologists who had earned doctorates within seven years of the female dendrochronologists and paired them together for comparison (Table 1-please note that the numbers assigned to each researcher in Table 1 identify that individual's rank within their gender, but do not identify the pairing between male and female researchers). This ensured the integrity of our data, because it was then impossible for the males to be all senior researchers and the females all junior researchers or vice versa. By using the same number of male and female dendrochronologists, we eliminated the over-representation of men, which would have resulted if we had taken a random sample from all dendrochronologists. Although sole-authored papers would 
Table 1. First-authored publication and citation record for 20 male and 20 female dendrochronologists. The numbers assigned to each researcher identify their rank within their gender with regards to citations, e.g. Female \#6 ranks sixth out of 20 females in terms of the average number of citations per firstauthored publication.

\begin{tabular}{|c|c|c|c|c|}
\hline Researcher & $\begin{array}{c}\text { Years } \\
\text { Since PhD } \\
\text { Completed }\end{array}$ & $\begin{array}{c}\text { \# First- } \\
\text { authored } \\
\text { ISI } \\
\text { Publications }\end{array}$ & $\begin{array}{l}\text { Total Cita- } \\
\text { tions of First- } \\
\text { authored } \\
\text { Publications }\end{array}$ & $\begin{array}{c}\text { Avg. \# } \\
\text { - Citations } \\
\text { Per } \\
\text { Publication }\end{array}$ \\
\hline Male \#1 & 22 & 9 & 1201 & 133.4 \\
\hline Male \#2 & 25 & 25 & 2165 & 86.6 \\
\hline Male \#3 & 24 & 27 & 1520 & 56.3 \\
\hline Female \#1 & 24 & 11 & 484 & 44.0 \\
\hline Female \#2 & 17 & 1 & 41 & 41.0 \\
\hline Male \#4 & 14 & 18 & 578 & 32.1 \\
\hline Female \#3 & 6 & 3 & 85 & 28.3 \\
\hline Male \#5 & 25 & 10 & 278 & 27.8 \\
\hline Female \#4 & 26 & 11 & 270 & 24.5 \\
\hline Female \#5 & 13 & 11 & 263 & 23.9 \\
\hline Male \#6 & 13 & 7 & 144 & 20.5 \\
\hline Female \#6 & 13 & 15 & 304 & 20.3 \\
\hline Male \#7 & 24 & 12 & 239 & 19.9 \\
\hline Female \#7 & 9 & 8 & 152 & 19.0 \\
\hline Female \#8 & 20 & 8 & 150 & 18.8 \\
\hline Female \#9 & 20 & 3 & 46 & 15.3 \\
\hline Male \#8 & 9 & 8 & 121 & 15.1 \\
\hline Male \#9 & 14 & 10 & 149 & 14.9 \\
\hline Male \#10 & 5 & 15 & 218 & 14.5 \\
\hline Female \#10 & 20 & 39 & 559 & 14.3 \\
\hline Female \#11 & 7 & 3 & 42 & 14.0 \\
\hline Male \#11 & 17 & 1 & 13 & 13.0 \\
\hline Male \#12 & 12 & 13 & 157 & 12.1 \\
\hline Male \#13 & 8 & 7 & 85 & 12.1 \\
\hline Female \#12 & 19 & 11 & 132 & 12.0 \\
\hline Female \#13 & 24 & 2 & 23 & 11.5 \\
\hline Male \#14 & 16 & 12 & 128 & 10.7 \\
\hline Male \#15 & 9 & 5 & 45 & 9.0 \\
\hline Female \#14 & 17 & 9 & 80 & 8.9 \\
\hline Female \#15 & 10 & 6 & 50 & 8.3 \\
\hline Male \#16 & 8 & 6 & 48 & 8.0 \\
\hline Female \#16 & 22 & 11 & 84 & 7.6 \\
\hline Male \#17 & 27 & 17 & 146 & 7.0 \\
\hline Male \#18 & 13 & 17 & 88 & 5.2 \\
\hline Male \#19 & 5 & 13 & 53 & 4.1 \\
\hline Female \#17 & 17 & 4 & 13 & 3.3 \\
\hline Female \#18 & 12 & 4 & 11 & 2.8 \\
\hline Male \#20 & 12 & 4 & 10 & 2.5 \\
\hline Female \#19 & 9 & 10 & 24 & 2.4 \\
\hline Female \#20 & 19 & 8 & 4 & 0.5 \\
\hline
\end{tabular}

truly represent the work and specific contributions of a male or female researcher, from within our sample of first-authored papers (418 papers total) only 81 of the papers $(19 \%)$ were sole authored.
Thus working with sole-authored papers would have considerably reduced our sample size and made for a less rigorous analysis. First-authored papers are important in early career stages, when decisions of funding and promotion are made. Inclusion of all publications of each dendrochronologist would have resulted in numerous papers being counted multiple times, because many of our male and female dendrochronologists had co-authored publications with each other. First-authorship is granted to the author who has made the largest intellectual contribution to that paper, so we examined only first-authored papers in this study. The fact that we worked with only first-authored papers also explains why we did not use the Hirsch " $\mathrm{H}$ " Index (Truex et al. 2009), which is calculated from a researcher's entire body of publications, when we examined citation rates. The dendrochronologists examined in this study included academic and government researchers from 16 countries (Argentina, Australia, Canada, China, Ethiopia, Germany, Italy, Morocco, New Zealand, Russia, Slovenia, South Africa, Sweden, Switzerland, United Kingdom, and the United States of America) and spanned six continents. The geographic representation of the researchers mirrored publication trends in general, with a higher proportion of researchers coming from developed countries than developing countries (Galvez et al. 2000).

Identification of all first-authored publications for each dendrochronologist was an iterative process that involved combining multiple sources (i.e. online websites and curricula vitae) to ensure that all first-authored publications in the Web of Science database were captured. This was necessary because Web of Science occasionally included a variety of spellings for an individual's name. Once a list of first-authored publications in the Web of Science database was obtained for each author, the number of times each paper was cited was recorded, and we used this number as the basis for evaluating scholarly recognition. To compare the number of citations between researchers, we divided the total number of citations each author received by the total number of firstauthored publications in order to calculate the average citations per first-authored publication (Table 1). Given that time since publication is 
known to influence the citation frequency of a paper (Standing 2009) and because senior scientists often co-author more than younger scientists, but publish fewer first-authored papers, we determined it was best to compare these values among dendrochronologists who have held their doctorates for a similar length of time. It is also important to understand that the list of firstauthored publications does not represent an individual's full body of scholarship. Many researchers authored articles that were in journals not included in the Web of Science database (especially a number of papers in Dendrochronologia, one of two exclusively dendrochronologydedicated journals, that was not included in Web of Science), and all individuals were co-authors on papers for which they were not the first author. However we only used articles located in the Web of Science database as a control method in our analysis, as this resource includes prominent journals across all fields of science, is accessible by many research institutions and also includes the "cited by" data we used in our calculations.

To evaluate gender bias in the citation rate of these dendrochronologists, we created a regression model that predicted the average citation rate based on gender (coded for male and female), current employment (coded for government institution and academic institution), years since completing doctorate (an indication of whether the scientist was of junior or senior rank), native language (coded for native English speaker and English as a second language), and productivity (total number of first-authored publications). We used a logarithmic transformation of the average citation rate because the residual plot showed an increasing variance and a non-linear trend. Nonsignificant $(p>0.1)$ factors were removed and the model was re-analyzed until only significant predictors remained in the model.

To address the issue of whether males and females publish in different caliber journals, which could misleadingly appear as a gender-based difference in citation rate, we selected six journals in which both the male and female dendrochronologists from this study published frequently. These six journals represented a span of impact-factor rankings provided by the 2008 Journal Citation
Reports and we examined the average citations by year since publication of the article for both female and male first-authored papers. The goal of this analysis was to identify whether a female firstauthored paper from a given journal would receive more, the same number, or fewer citations as compared to a male first-authored paper from the same journal. To test the significance between the males and females, we used a t-test to compare the average citations by year since publication for male and female first-authored papers in the following journals that each had at least three articles published by both male and female authors: Canadian Journal of Forest Research (2008 Impact Factor $=1.434)$, Forest Ecology and Management (2008 Impact Factor = 2.110), Geophysical Research Letters (2008 Impact Factor = 2.959), Holocene (2008 Impact Factor = 2.167), Nature (2008 Impact Factor $=31.434)$, and Tree-Ring Research (2008 Impact Factor $=0.300$ ). Significance was defined as $\mathrm{p}<0.05$.

\section{RESULTS AND DISCUSSION}

Native language $(\mathrm{p}=0.92)$, current employment $(\mathrm{p}=0.64)$, productivity $(\mathrm{p}=0.53)$, and gender $(\mathrm{p}=0.27)$ were not significant in determining average citation rate. However, the years since completing doctorate $\left(\mathrm{r}^{2}=0.09, \mathrm{p}=\right.$ 0.06) proved to be a marginally significant predictor for average citation rate with senior researchers (those for whom it has been a longer time since they completed their doctorates) having higher citation rates than junior researchers. The resulting regression equation was

$$
\mathrm{Y}=1.7976+0.048 \times(\text { Years since doctorate })
$$

where $\mathrm{Y}$ is defined as the natural log of average citations per publication (Figure 1). The datum for Female \# 20 (Table 1) appears as an outlier in this regression (Figure 1) and when the same regression is fitted withholding this datum, the fit improved $\left(\mathrm{r}^{2}=0.16, \mathrm{p}=0.01\right)$.

Of the six journals specifically compared for gender differences in citations rates (Table 2), none of the journals had significant differences in citations by sex (Canadian Journal of Forest Research: $\mathrm{t}=0.13, \mathrm{p}=0.90 ;$ Forest Ecology and 


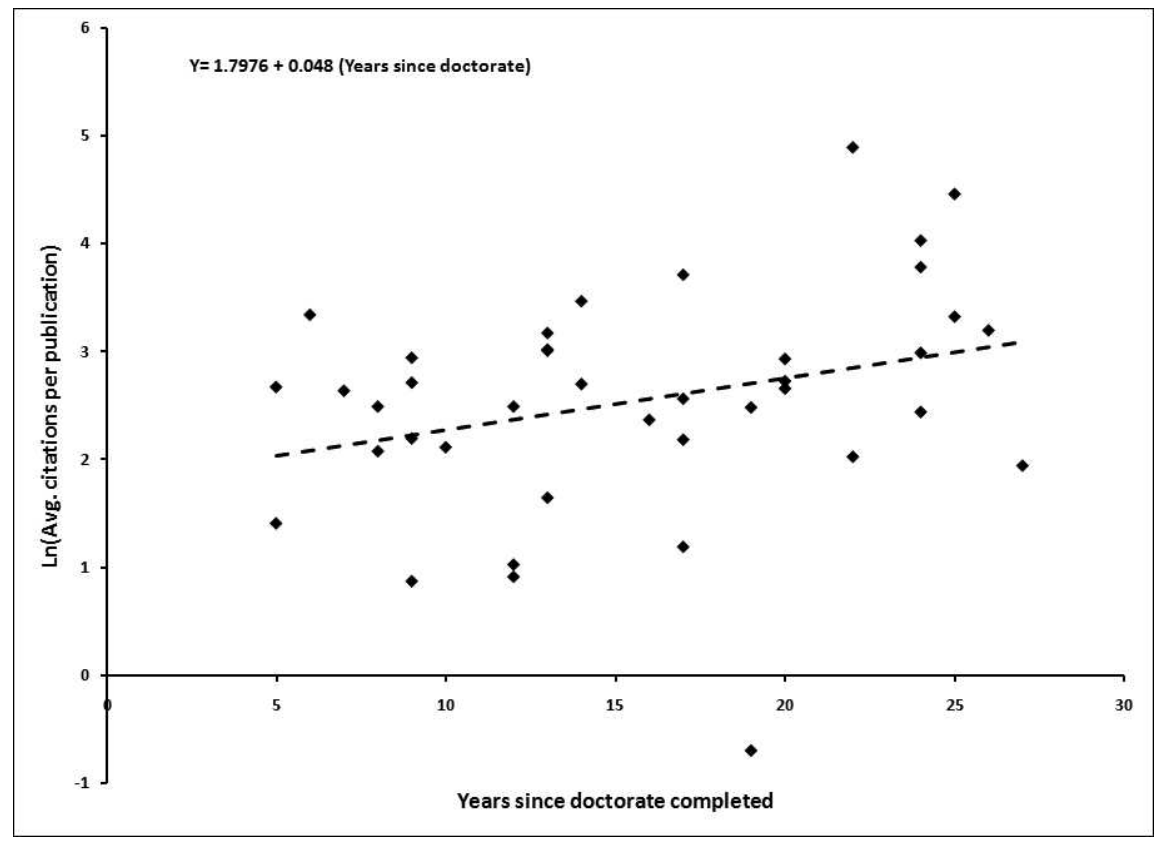

Figure 1. In this plot, number of years since dissertation completed $\left(r^{2}=0.09, p=0.06\right)$ is only a marginally significant predictor of citation rate for publications by dendrochronologists. Other factors, such as native language (English or non-native English speaker), current employment (government or academic) and researcher productivity, were not significant.

Management: $\mathrm{t}=-1.48, \mathrm{p}=0.20 ;$ Geophysical Research Letters: $\mathrm{t}=0.72, \mathrm{p}=0.51$; Holocene: $\mathrm{t}=$ $-1.58, \mathrm{p}=0.15$; Nature: $\mathrm{t}=0.29, \mathrm{p}=0.79$; and Tree-Ring Research: $\mathrm{t}=-1.4, \mathrm{p}=0.23$ ).

The lack of a gender bias in citation rates of women's scholarship in the field of dendrochronology is unusual and contrasts with significantly lower citation rates for women-authored papers in sociology and library science (Ward et al. 1992; Davenport and Snyder 1995; Hakanson 2005). What is unique about dendrochronology that makes gender immaterial for citation rate? One possible reason is that female dendrochronologists are highly productive researchers, something that is not found in other disciplines where women's publication productivity lags behind men's (Wilson et al. 1999; Dorsey et al. 2006; Frietsch et al. 2009). Among dendrochronologists, there was no significant difference $(\mathrm{t}=-1.31, \mathrm{p}=0.20)$ in the average number of first-authored papers published by men (average 12 papers) vs. women (average 9 papers). However, given that our top three mosthighly cited dendrochronologists were all male, dendrochronology may be prone to the same pattern seen in other disciplines where the "star scientists," those with the highest productivity and recognition, are all or mostly male (Abramo et al. 2009). In criminal justice, lower productivity for female researchers has been ascribed to higher levels of service and teaching and shorter career spans (Snell et al. 2009). Although many dendrochronologists in traditional academic positions incorporate tree-ring projects in geography, biology, or forestry classes, dendrochronology is not a part of a normal undergraduate curriculum (Lafon 2005). This lack of a direct link to undergraduate education leads to an over-representation of dendrochronologists, compared to other disciplines, who work in positions where they are able to devote more time to research with fewer teaching obligations. From our dataset, $40 \%$ of the women were in positions where a majority of their time was devoted to research (e.g. government research institutions or agencies), which probably allows them to have higher productivity rates than female researchers in more teachingoriented disciplines.

The frequency with which female dendrochronologists choose to co-author papers may also lessen gender bias in citation rates. The tendency of 
Table 2. Average number of citations received per published paper for male and female dendrochronologists in six common journals in which dendrochronologists published. These data come from 20 female and 20 male dendrochronologist's firstauthored papers.

\begin{tabular}{lcc}
\hline \multirow{2}{*}{ Journal } & \multicolumn{2}{c}{$\begin{array}{c}\text { Average Citation } \\
\text { Rate Per Year }\end{array}$} \\
\cline { 2 - 3 } & Females & Males \\
\hline Canadian Journal of Forest Research & 1.5 & 1.4 \\
Forest Ecology and Management & 0.6 & 1.2 \\
Geophysical Research Letters & 5.0 & 2.8 \\
The Holocene & 0.8 & 3.3 \\
Nature & 9.5 & 7.3 \\
Tree-Ring Research & 0.4 & 0.9 \\
\hline
\end{tabular}

women to co-author papers at a different rate than men is discipline specific; in some fields women coauthor papers in equal numbers to men (McDowell et al. 2005), in other fields women have significantly lower rates of co-authorship (Boschini and Sjogren 2007), and in others women co-author more frequently than men (Aleixandre-Benavent et al. 2007). Collaboration with male co-authors brings female-authored publications to the attention of male-academic networks that are much more effective at gaining recognition than female networks (Hanson 2000). Therefore it is advantageous for women to co-author papers. Within our group of dendrochronologists, $78 \%$ of all publications authored by female dendrochronologists were coauthored and $80 \%$ of male dendrochronologists were co-authored. Thus, female dendrochronologists co-author publications at a similar rate to male dendrochronologists. This removes the isolation of sole-authorship experienced by women in some disciplines and may also contribute to the lack of gender bias in citation rates.

Another contributing factor to the lack of gender bias could be that female scientists place a greater emphasis on publications rather than on other research outputs, such as patents, which results in higher quality of articles produced by women (Winkler 2000; Frietsch et al. 2009). Although women often comprise a smaller proportion of researchers, their publications appear in significantly higher-ranked journals as compared to their male counterparts (Housri et al. 2008). This higher quality may counter any gender bias in citation rates. However, the pattern of higher quality publications coming from female-authors was not clear in our dataset because the top ten most-cited articles were all authored by men (Males \#1-3). This does not imply that female dendrochronologists produce lower quality of scholarship, but it does demonstrate that unlike observations in physical geography and medical research (Winkler 2000; Housri et al. 2008), women dendrochronologists publish articles that are on average cited at the same rate as their male colleagues.

This paper demonstrates that females publishing in the area of dendrochronology do not experience a significant gender bias in the citation rates of their publications. However, this does not imply that female dendrochronologists do not experience other types of gender bias and we do not intend to belittle the challenges that women dendrochronologists have overcome to gain the same level of recognition of their research as their male counterparts. If anything we laud the efforts of women researchers who overcome well-documented biases in hiring processes (Levin et al. 2005; Schmader et al. 2007), promotion decisions (Carr et al. 2003; Heilman and Okimoto 2008), tenure decisions (Luzzadder-Beach and Macfarlane 2000), and grant awarding (Bornmann and Daniel 2005; Bornmann et al. 2007) to achieve the same level of success as their male counterparts.

\section{REFERENCES CITED}

Abramo, G., C. A. D'Angelo, and A. Caprasecca, 2009. The contribution of star scientists to overall sex differences in research productivity. Scientometrics 81:137-156.

Aleixandre-Benavent, R., G. Gonzalez-Alcaide, A. AlonsoArroyo, M. Castellano-Gomez, and J. C. ValderramaZurian, 2007. Gender analysis among articles published in Enfermedades Infecciosas y Microbiologia Clinica. Engermedades Infecciosas y Microbiologia Clinica 25:619-626.

Bornmann, L., and H. D. Daniel, 2005. Selection of research fellowship recipients by committee peer review. Reliability, fairness and predictive validity of Board of Trustees' decisions. Scientometrics 63:297-320.

Bornmann, L., R. Mutz, and H. D. Daniel, 2007. Gender differences in grant peer review: A meta-analysis. Journal of Informetrics 1:226-238.

Boschini, A., and A. Sjogren, 2007. Is team formation gender neutral? Evidence from coauthorship patterns. Journal of Labor Economics 25:325-365. 
Bredenkamp, C. L., and G. F. Smith, 2008. Perspectives on botanical research publications in South Africa: An assessment of five local journals from 1988 to 2002, a period of transition and transformation. South African Journal of Science 104:473-478.

Carr, P. L., L. Szalacha, G. Caswell, and T. Inui, 2003. A "ton of feathers": Gender discrimination in academic medical careers and how to manage it. Journal of Women's Health 12: $1009-1018$.

Cherubini, P., 2008. Impact factor fever. Science 322:191.

Davenport, E., and H. Snyder, 1995. Who cites women? Whom do women cite? An exploration of gender and scholarly citation in sociology. Journal of Documentation 51:404 410.

Dorsey, E. R., B. A. Raphael, L. J. Balcer, and S. L. Galetta, 2006. Predictors of future publication record and academic rank in a cohort of neurology residents. Neurology 67:1335-1337.

Dries, N., R. Pepermans, and O. Carlier, 2008. Career success: Constructing a multidimensional model. Journal of Vocational Behavior 73:254-267.

Feramisco, J. D., J. J. Leitenberger, S. I. Redfern, A. H. Bian, X. J. Xie, and J. S. Resneck, 2009. A gender gap in the dermatology literature? Cross-sectional analysis of manuscript authorship trends in dermatology journals during 3 decades. Journal of the American Academy of Dermatology 60:63-69.

Frietsch, R., I. Haller, M. Funken-Vrohlings, and H. Grupp, 2009. Gender-specific patterns in patenting and publishing. Research Policy 38:590-599.

Galvez, A., M. Maqueda, M. Martinez-Bueno, and E. Valdivia, 2000. Scientific publication trends and the developing world. American Scientist 88:526-533.

Hakanson, M., 2005. The impact of gender on citations: An analysis of College \& Research Libraries, Journal of Academic Librarianship, and Library Quarterly. College \& Research Libraries 66:312-322.

Hanson, S., 2000. Networking. Professional Geographer 52: 751-758.

Heilman, M. E., and T. G. Okimoto, 2008. Motherhood: A potential source of bias in employment decisions. Journal of Applied Psychology 93:189-198.

Housri, N., M. C. Cheung, L. G. Koniaris, and T. A. Zimmers, 2008. Scientific impact of women in academic surgery. Journal of Surgical Research 148:13-16.

Lafon, C. W., 2005. Reconstructing fire history: An exercise in dendrochronology. Journal of Geography 104:127-137.

Levin, I. P., R. M. Rouwenhorst, and H. M. Trisko, 2005. Separating gender biases in screening and selecting candidates for hiring and firing. Social Behavior and Personality 33: 793-804.

Luzzadder-Beach, S., and A. Macfarlane, 2000. The environment of gender and science: Status and perspectives of women and men in physical geography. Physical Geography 52:407-424.

McDowell, J. M., L. D. Singell, and M. Stater, 2005. Two to Tango? Gender differences in the decisions to publish and coauthor. Economic Inquiry 44:153-168.

McElhinny, B., M. Hols, J. Holtzkener, S. Unger, and C. Hicks, 2003. Gender, publication and citation in sociolinguistics and linguistic anthropology: The construction of a scholarly canon. Language in Society 32:299-328.

Penas, C. S., and P. Willett, 2006. Gender differences in publication and citation counts in librarianship and information science research. Journal of Information Science 32: 480-485.

Schmader, T., J. Whitehead, and V. H. Wysocki, 2007. A linguistic comparison of letters of recommendation for male and female chemistry and biochemistry job applicants. Sex Roles 57:509-514.

Snell, C., J. Sorensen, J. J. Rodriguez, and A. Kuanliang, 2009. Gender differences in research productivity among criminal justice and criminology scholars. Journal of Criminal Justice 37:288-295.

Stack, S., 2002. Gender and scholarly productivity: The case of criminal justice. Journal of Criminal Justice 30:175-182.

Standing, L. G., 2009. Public recognition of major works in psychology: Rise and fall over time. Social Behavior and Personality 37:145-148.

Symonds, M. R. E., N. J. Gemmell, T. L. Braisher, K. L. Gorringe, and M. A. Elgar, 2006. Gender differences in publication output: Towards an unbiased metric of research performance. PloS One 1:e127.

Tol, R. S. J., 2009. The Matthew effect defined and tested for the 100 most prolific economists. Journal of the American Society for Information Science and Technology 60:420-426.

Truex, D., M. Cuellar, and H. Takedo, 2009. Assessing scholarly influence: using the Hirsch indices to reframe the discourse. Journal of the Association for Information Systems 10:560-594.

Ward, K. B., J. Gast, and L. Grant, 1992. Visibility and dissemination of women's and men's sociological scholarship. Social Problems 39:291-298.

Wilson, C. D., M. A. Hossain, B. Lubin, and M. Malebo, 1999. Gender and scholarly productivity in Administration in Social Work, 1977-1995. Administration in Social Work 23: $67-83$.

Winkler, J. A., 2000. Faculty reappointment, tenure, and promotion: Barriers for women. Professional Geographer 52:737-750.

Received 21 July 2009; accepted 22 February 2010. 